\title{
OBJETOS PEDAGÓGICOS/ATIVIDADES LÚDICAS PARA A COMPREENSÃO DA ARTE E PARA A INCLUSÃO SÓCIO-CULTURAL.
}

\author{
Prof $^{a}$ Doutora Maria Cristina da Rosa Fonseca da Silva ${ }^{1}$, Cristiane Higueras Simó ${ }^{2}$
}

Palavras-chave: Arte/Educação, Objetos Pedagógicos, Inclusão Social, Necessidades Especiais.

\section{Resumo:}

O presente artigo refere-se aos fundamentos teórico-práticos que sustentam a pesquisa de mestrado com o objeto de investigar a importância da arte como facilitadora no processo de inclusão sócio-cultural de pessoas com necessidades especiais, assim como, identificar objetos pedagógicos e atividades lúdicas como ferramentas mediadoras para estudo e compreensão da arte. A pesquisa de mestrado estará dando continuidade à pesquisa de Iniciação científica realizada em 2003 pelo Centro Universitário de Belas Artes de São Paulo com o tema "A Contribuição da Arte na Formação do Cidadão e na Inclusão Social de Pessoas com Síndrome de Down".

\section{Apresentação}

O trabalho tem como foco principal reconhecer o desenvolvimento cognitivo que ocorre em pessoas que tem a possibilidade de interpretar o seu cotidiano, o mundo em que está inserido mediante a percepção da arte. Acredita-se que a percepção será instigada com o uso e criação de objetos pedagógicos e atividades lúdicas para a interpretação da arte e da cultura visual a fim de estimular em cada participante, seja ele observador ou criador, o seu modo de pensar, interpretar, conceber possibilidades, construir metáforas assim como decifrá-las, diferenciar e comparar situações, lugares, épocas e possibilidades. "Desconstruir para reconstruir, selecionar, reelaborar, partir do conhecido e modificá-lo de acordo com o contexto e a necessidade são processos criadores desenvolvidos pelo fazer e ver arte, e decodificadores fundamentais para a sobrevivência no mundo cotidiano". (BARBOSA,2005, p.100). Considerando o processo educativo nas aulas de arte em classes regulares, os objetos pedagógicos ampliam as possibilidades de construir e reconstruir o saber artístico. Ocorre que no processo de formação artística as pessoas com necessidades especiais, podem utilizar-se de objetos pedagógicos nas classes regulares, para aproximarem-se da aprendizagem coletiva.

\footnotetext{
${ }^{1}$ Professora doutora do CEAD e do PPGAV/CEART. ${ }^{2}$ Mestranda do PPGAV/CEART
} 


\section{Arte e Cognição - Arte e Cultura.}

Alguns autores verificaram a importância da arte no desenvolvimento cognitivo como Rudolf Arnheim que tinha como concepção a equivalência configuracional entre percepção e cognição, isto é, perceber é conhecer (BARBOSA, 2005).

$\mathrm{O}$ objeto artístico revela conceitos culturais, tais conceitos referem-se a atitudes, costumes, crenças filosóficas e religiosas. É na arte que estes conceitos ganham formas concretas, possibilitando ao observador se situar em relação ao passado, presente e futuro, proporcionado ao indivíduo a interpretação e a criação de símbolos que traduzem emoções e sentidos. Segundo David Thistlewood apud, Barbosa, (2005) quando as imagens artísticas são descobertas por outros e assim gradualmente propagadas através de amplos círculos de apreciação, elas alcançam a aceitação geral e passam a ser agentes de identificação de grupo.

A arte como forma de representação cultural, apresenta uma combinação de significados ligados a signos construídos por um povo a fim de facilitar a comunicação entre as pessoas. Mesmo os grupos caracterizados como "minorias" também trazem culturas, com isso arte, desenvolvendo esta arte em sua comunidade. É importante que todos reconheçam a multiculturalidade existente em uma sociedade para que assim todos se sintam incluídos e que percebam construtores da cultura em que estão inseridos.

A educação através da arte possibilita efetuar uma "re-construção" do que entendemos sobre a nossa cultura podendo extrair princípios de significação socioeconômica e cultural. A inclusão sócio cultural encontra na arte, e mais ainda, na arte/educação um meio facilitador, pois, o estudante percebe que sua experiência é de grande importância, com inúmeros significados os quais dão sentido ao mundo e que podem ser expressados no objeto artístico. O indivíduo tem a possibilidade de relacionar as suas histórias pessoais, as suas vivências aos aspectos culturais, as crenças existentes e aos diferentes pontos de vista. Estas relações ajudam a construir o conhecimento. Como lembra Hernández (2000) a aprendizagem no campo artístico utiliza estratégias intelectuais como a análise, a interferência, o planejamento e a resolução de problemas ou formas de compreensão e interpretação.

A aprendizagem da arte no âmbito educacional consiste no processo pedagógico onde os alunos constroem saberes culturais e estéticos, mediante reflexões, contextualização, produções e apreciações artísticas os quais possibilitam, a cada

DAPesquisa, Florianópolis, v.3 n.5, p.061-070, 2008. 
indivíduo, interagir com a sociedade na qual está inserido e assim formar-se e desempenhar-se como cidadão. Mediante o fazer, os processos reflexivos e os conceitos artísticos, percebe-se o quanto o homem é capaz de criar novas soluções para atender tanto suas necessidades, quanto seus prazeres.

A arte possibilita a reflexão sobre a história e a cultura no contexto social humano. Em muitos trabalhos artísticos, são expressas questões humanas como, problemas sociais e políticos, relações humanas, sonhos, medos, perguntas e inquietações, fatos históricos e manifestações culturais. "O que mais caracteriza a unidade de um país, senão sua música, seu teatro, suas formas e cores, sua dança, folclore, poesia? Nessas manifestações, sempre fruto de um amálgama cultural, é que estão mais fortemente gravados os sentimentos e pensamentos de um povo”. (Martins, 1998:10) A arte é um meio de expressão simbólica e de conhecimento. Quando alguém se manifesta artisticamente, está se comunicando com o mundo, deixando no seu fazer artístico sua identidade, suas características. É um fazer subjetivo, trabalha o sensível e o imaginário, o qual se torna um registro fiel das manifestações humanas, conseqüentemente da história do mundo. Segundo Zanella "A questão do olhar vem se constituindo como um dos principais temas de reflexão na contemporaneidade". 2004,p.52). A arte na escola tem como tarefa principal ampliar o leque desse olhar partindo da cultura local para os aspectos mais amplos da arte e da sociedade e viceversa.

Considerando que a cultura contém todas as produções, trabalhos, expressões, e relações sociais de um grupo social, é na arte que ela melhor se desenvolve. Ao se expressar artisticamente, o indivíduo busca em seu repertório, adquirido com sua vivência no contato com diversas culturas, um significado para si, comunicando esta síntese de saberes para outros indivíduos. Contribuindo assim, para a cultura de sua época. $\mathrm{O}$ homem gera cultura e se constitui homem na cultura.

\section{A Arte como facilitadora da Inclusão Social}

No âmbito das tendências pedagógicas na atualidade, a inclusão constitui-se como um termo amplo e polissêmico, pois surge no contexto do movimento de inclusão que chega ao Brasil na década de 1990 e que propõe como meta educacional "Educação para Todos". Nessa abordagem a inclusão social se consolida como um termo mais amplo que abarca não só os grupos etnicamente diferenciados, como também as pessoas 
com necessidades especiais e as classes populares que se concentram na maior parte das vezes entre os grupos já estigmatizados socialmente.

As sociedades muitas vezes excluem determinados grupos de pessoas, como os que apresentam necessidades especiais e os de baixa renda, por diferentes aspectos, causando assim a discriminação e fazendo com que determinados grupos não tenham acesso aos bens culturais ou que este acesso seja realizado de forma desqualificada. Não apenas aos bens culturais, mas muitas pessoas por não terem oportunidades, são excluídas socialmente prejudicando a sua percepção cultural em relação ao mundo que está inserido, ao reconhecimento de sua importância como construtor da cultura, e ao conhecimento da multiculturalidade. O fato resulta muitas vezes em violência social, ou confinamento em ambientes "protegidos".

E como contribuir para amenizar esta situação? Ou mesmo abolir este tipo de relação social? A Arte existe não apenas para favorecer a pessoa que cria, sendo este um fator muito importante para o desenvolvimento cognitivo e como aguçadora dos sentidos, mas sua importância também existe por favorecer diversas formas de interpretações, transmitindo significados que não podem ser passados por meio de nenhum outro tipo de linguagem, favorecendo assim o desenvolvimento cognitivo do observador, do leitor de arte. Neste sentido tal como a Arte a percepção da Cultura Visual proporciona ao observador, formular hipóteses, diagnosticar, generalizar, relacionar por semelhanças e diferenças o seu entorno mediante a interpretação de formas, cores, usos, funções, possibilitando ações na sociedade em que está inserido, valorizando e reafirmando a sua cidadania.

A Arte é o social em nós. O social não é apenas o coletivo, assim como as raízes e a essência da arte não são individuais[...]É uma atividade de fundo social na qual o homem se forma e interage com seus semelhantes e seu mundo numa relação intercomplementar de troca[...]O enfoque estético da arte deve combinar as vivências do ser humano em nível individual com a recepção do produto estético percebido como produto social e cultural (Vigotsky, 2001:XII).

A comunicação de determinado conhecimento possibilita a aproximação entre indivíduos, mesmo de culturas distintas. A arte possibilita esta interação mediante produtos artísticos e concepções estéticas expressas de um modo diferenciado da linguagem discursiva. 
A arte não exclui, ela é democrática, pois o indivíduo expõe o seu modo de ver o mundo, tanto como observador como criador. A arte abre espaço para o desenvolvimento das múltiplas inteligências, dos componentes intuitivos, sensoriais, e a percepção espacial, independentemente de limites físicos ou fisiológicos. Segundo Barbosa (2005), o produtor de arte tem grandes chances de ser bem sucedido nas artes, de sentir-se aprovado, ter seu ego cultural reforçado e, assim, se desenvolver cognitivamente. A Arte-Educação não lida com certo e o errado, mas com o provável, o imaginável.

\section{Educação e inclusão.}

Seguindo as tendências internacionais a educação deu um grande passo no que se refere aos indivíduos que apresentam claramente, condições individuais que defrontamse com as condições gerais da educação formal, principalmente no âmbito das formulações teóricas e da legislação (Fonseca da Silva; Bornelli 2008). São indivíduos que apresentam necessidades educacionais especiais, estando impossibilitados por problemas orgânicos de acompanhar alunos da mesma faixa etária em escolas regulares. O quadro da inclusão de fato, mesmo em Estados brasileiros mais desenvolvidos é bastante excludente. Esta situação refere-se principalmente a três aspectos, falta de infra-estrutura básica na rede escolar, falta de formação continuada dos professores e falta de vontade política de facilitar a inclusão por parte dos governantes.

O grupo de pessoas, que apresentam algum tipo de necessidade especial, é prejudicado pelo atual sistema de ensino, pois ao valorizar apenas as inteligências lingüísticas e lógico-matemáticas, a escola acaba por não estimular outras competências que podem ser geniais. Gardner (1997) traz importantes contribuições a esse respeito. Portanto, não se deve trabalhar a educação especial isoladamente, pois assim, continuará a fortalecer a segregação. Existe a necessidade da interação do sistema educacional especial com o sistema regular de ensino, a fim de integrar todos os alunos sem exclusão, e retirar a educação especial do contexto paralelo da educação.

Para um efetivo sistema de inclusão, segundo Lunardi, Mendes e Fonseca da Silva (2008) as escolas regulares, devem adaptar no seu currículo, métodos novos e criativos que permitam a participação de alunos com necessidades educativas especiais a fim de garantir a aprendizagem a todos os cidadãos.

O sistema educativo inclusivo, o qual apóia as necessidades educativas especiais, não é apenas um sistema de ensino de educação especial tradicional, mas um sistema 
que utiliza metodologias que constroem a inclusão no grupo, que possibilitam um atendimento qualificado no contexto da sala de aula, inclusive com reforço na escola regular. Sugere a reestruturação dos programas tradicionais, com o intuito de responder à diversidade dos alunos que freqüentam a escola.

A educação inclusiva descreve o processo através do qual a escola tenta responder a todos os alunos enquanto indivíduos, reconhecendo e reestruturando a sua organização curricular e a provisão e utilização de recursos para melhorar a igualdade de oportunidades. Através deste processo, a escola constrói a sua capacidade de aceitar todos os alunos que a desejem freqüentar provenientes da comunidade local e, fazendo isto, reduz a necessidade de excluir alunos (in Warwick,Cliff. Sebba e Ainscow. Apoio às escolas inclusivas. Disponível em: http://www.deb.min-edu.pt/revista/revista5/cliff\%20Warwick.htm)

O processo de Inclusão Educacional, defende a idéia de que a aprendizagem deve beneficiar do mesmo modo todos os indivíduos, propõe a interação de todos em todas as situações, respeitando em ambos os casos suas necessidades e particularidades. Neste caso os objetos pedagógicos funcionam como ferramentas que ampliam a participação das pessoas com necessidades especiais nas classes regulares. Pode-se tomar como exemplo uma classe com um aluno com Paralisia Cerebral (PC), onde a linguagem do jogo se constitua através de cartaz, como no sistema de comunicação dos PCs, que utiliza-se do desenho universal como forma de comunicação. Neste caso as linguagens tradicionais são deixadas de lado e a aprendizagem se constitui a partir das características dos deficientes. Sousa afirma:

Incluir não é somente delegar à criança um espaço físico em sala de aula, é propor ao indivíduo atividades significativas capazes de promover seu desenvolvimento e remover as barreiras a seu acesso e participação na aprendizagem e na sociedade. Ressalvando (mas não ressaltando), sempre, que todos podem apresentar dificuldades em alguma área do conhecimento ou etapa da vida. As limitações existem em qualquer indivíduo, o que não significa que não possa ser um indivíduo participativo ou capaz de aprender. (SOUSA, Luciane Porto Frazão de. Educação Especial:Redefinir ou continuar excluindo? Disponível em: http://www.psicopedagogia.com.br/artigos/print.asp?entrID=369) 
Para a transformação de uma sociedade, no que se refere à saúde e a educação, deve-se reconhecer a diversidade das características das pessoas, em relação às capacidades mentais, físicas, motoras, as diferentes etnias e idiossincrasias. Nas mudanças da humanidade são geradas melhorias na qualidade de vida, deve-se conviver com as diferenças, a fim de respeitá-las e facilitar a socialização de todos os indivíduos.

\section{Objetos Pedagógicos/Atividades Lúdicas.}

Os objetos pedagógicos inclusivos vêm sendo criados e utilizados por educadores com o intuito de melhor promover o estudo da arte e a inclusão social na educação, criando adaptações que favoreçam situações de aprendizagem em turmas de alunos regulares com a presença de alunos que tenham necessidades especiais.

O objeto pedagógico/atividades lúdicas é um instrumento utilizado, (sendo considerado alternativo, isto é, a interpretação de uma obra de arte pode ser feita sem ele) para melhor compreender uma obra ou um conjunto de obras de arte. São jogos ou atividades lúdicas que estimulam as diferentes maneiras de interpretação e de contextualização de uma obra. São jogos que não valorizam o ganhar ou perder, mas o participar, o "viajar" pelos elementos compositivos (formais), subjetivos e descritivos que envolvem o objeto de estudo.

Este tipo de atividade e de instrumentos vem sendo criados e utilizados por um grande número de museus no setor educativo. As exposições de arte muitas vezes acompanham uma atividade paralela ou pode-se dizer complementar para que os estudantes ou apreciadores da exposição possam ter um olhar mais atento referente ao que foi visto na exposição. A atividade lúdica proporciona ao participante relacionar objetos do seu cotidiano com formas encontradas na composição artística, com temas presentes na história instigando a reflexão de sua própria história, com o multiculturalismo, com as texturas, as cores, as sensações e emoções.

Este tipo de atividade proporciona um estudo mais profundo das artes visuais de maneira prazerosa, como se estivesse brincando, valorizando as brincadeiras das crianças, proporcionando às diferentes pessoas criarem diferentes interpretações, e assim continuar a construir história e cultura.

O Lúdico e o criativo são elementos constituintes dos homens que conduzem o viver para formas mais plenas de 
realização; são portanto, indispensáveis para uma vida produtiva e saudável, do ponto de vista da auto-afirmação do homem como sujeito, ser único, singular, mas que prescinde dos outros homens para se realizar como ser social e cultural, formas imanentes à vida humana . (BARTHOLO, 2001, in FERREIRA; VASCONSELOS; GOMES; ROCHA 2004)

Algumas pesquisas com o foco no ensino de arte tem abordado o tema da inclusão, destacam-se Nunes (2006), Lopes (2004), Fonseca da Silva (2007 e 2008). Com o intuito de ampliar as possibilidades de inclusão na sala de aula de artes, Fonseca da Silva desenvolveu nos anos de 2006 a 2008, extensa investigação com professores de artes a fim de diagnosticar o processo de inclusão em sala de aula regular. $\mathrm{Na}$ atualidade começam a surgir um número maior de pesquisas nesta temática, que carece de ampliar o leque investigativo que instigue práticas inclusivas na aula regular de arte.

\section{Considerações finais:}

As conclusões parciais do presente texto identificam que, mesmo passados 18 anos o início da inclusão no Brasil, o movimento é deficitário, atingindo parcialmente seus objetivos. Destaca-se também o reduzido número de trabalhos acadêmicos que investiguem a prática pedagógica do professor de arte em classes inclusivas. Ainda os estudos que consideram os processos artísticos das pessoas deficientes, bem como, o trabalho de inclusão em arte nas instituições não governamentais. Acredita-se que, ao final o recorte teórico aqui apresentado poderá servir de estofo inicial para as primeiras incursões a campo. Deste modo ressaltasse a importância da Arte e da Cultura Visual como um meio facilitador da inclusão de pessoas com necessidades especiais no contexto social e cultural. Consequentemente esta inclusão proporcionará a melhoria na qualidade de vida das pessoas. As ações pedagógicas investigadas no processo de pesquisa proporcionam a ampliação do olhar do investigador sobre os trabalhos artísticos das pessoas com deficiência.

Segundo Ballengee-Morris, (apud, BARBOSA,p.2005) todas as formas de educação atuam como intervenção social e a implementação disso leva à reconstrução da sociedade. Os conceitos do multiculturalismo-crítico ${ }^{3} \mathrm{em}$

\footnotetext{
${ }^{3}$ Sobre o multiculturalismo crítico ver Fonseca da Silva (2004)
} 
arte/educação, deve ser continuamente, um processo para encorajar a justiça e o desenvolvimento social, tornando as comunidades construtivas.

\section{Bibliografia:}

BARBOSA, Ana Mãe. Imagem do Ensino da Arte. São Paulo: Perspectiva,2002. BARBOSA, Ana Mãe (Org.). Arte/Educação Contemporânea, Consonâncias Internacionais. São Paulo: Cortez, 2005.

BARTHOLO, Márcia Fernandes. O lazer numa perspectiva lúdica e criativa. 2001. In O LÚDICO NOS ADULTOS: UM ESTUDO EXPLORATÓRIO NOS FREQÜENTADORES DO CEPE - NATAL/RN. FERREIRA, Andréa Francos;

VASCONCELOS, Ana Karoliny da Cruz; GOMES, Cynthia Valéria Barbosa; ROCHA, Marcilma Galvão. 2004

FONSECA da SILVA, Maria Cristina da Rosa (coord). BORNELLI, Margarete Cascaes. III Jornada de Pesquisa do CEART. $17^{\circ}$ Seminário de iniciação Científica da Udesc. Florianópolis. Out/2007.

FONSECA da SILVA, Maria Cristina da Rosa (coord). BORNELLI, Margarete Cascaes. Inclusão: Aspectos Legais e Educacionais. In: VII Seminário de Pesquisa em Educação da Região Sul - Anpedesul, 2008, Itajaí. VII Seminário de Pesquisa em Educação da Região Sul - Pesquisa em Educação e Inserção Social. Itajaí : Univali, 2008 .

FONSECA da SILVA, Maria Cristina da Rosa. A educação de professoras e professores de arte: construindo uma proposta de ensino multicultural a distância. 187p. Tese (Doutorado). Universidade Federal de Santa Catarina, Florianópolis, 2004.

FONSECA da SILVA, M. C. R. ; LUNARDI, G. M. . The concept of school inclusion: Are researchers and policy makers saying the same thing?. In: 2nd International Conference on Special Education, 2008, Marmaris. BOOK OF ABSTRACTS: Sharing Knowledge \& Experience Around The World. Marmaris : University Anadolu, 2008. v. 1. p. 04-345.

GARDNER, Howard. As Artes e o Desenvolvimento Humano. Porto Alegre: Artes Médicas, 1997.

HERNÁNDEZ, Fernando. Cultura Visual e Projeto de Trabalho. Porto Alegre: Artmed, 2000. 
LOPES,Ana Elizabete Rodrigues de Carvalho. Olhares Compartilhados: o ato fotográfico como experiência alteritária e dialógica. Rio de Janeiro, 2004, 262p. Tese de Doutorado. PUC - RJ.

MARTINS, Mirian Celeste; PICOSQUE, Gisa; Guerra, M. Terezinha Telles. Didática do Ensino de Arte. FTD. São Paulo, 1998.

Ministério da Educação. PARÂMETROS CURRICULARES NACIONAIS Terceiro e quart ciclos do ensino fundamental / Artes. Brasília, 1998.

NUNES, Ana Luiza Ruschel (org). O ensino das Artes Visuais: uma abordagem simbólico-cultural. Santa Maria, Ed. Da UFSM, 2006

Quais os Benefícios que a inclusão traz? Disponível em: http://wm3.ig.com.br/inmail/inmail.pl?acao. Acesso em: 29/01/03.

SIMÓ, Cristiane Higueras. Pesquisa de Iniciação Científica: A Contribuição da Arte na Formação do Cidadão e na Inclusão Social de Pessoas com Síndrome de Down. São Paulo: Centro Universitário Belas Artes de São Paulo, 2003.

SOUSA, Luciane Porto Frazão de. Educação Especial:Redefinir ou continuar excluindo? Disponível em: http://www.psicopedagogia.com.br/artigos/print.asp?entrID=369)

WARWICK,CLIFF . Apoio às escolas inclusivas. Disponível em: http://www.deb.minedu.pt/revista/revista5/cliff\%20Warwick.htm

WERNECK, Cláudia. Muito Prazer Eu Existo. WVA. Rio de Janeiro, 1995

VIGOTSKY, L.S. Psicologia da Arte. São Paulo, Martins Fontes, 2001.

ZANELLA, Andréia Vieira. Mediação pedagógica: reflexões sobre o Olhar estético em contexto de escolarização formal. Revista de Reflexão e Crítica. 200417(1).p. 51-60. 